\title{
CYP2C8 and CYP2C9 polymorphisms in relation to tumour characteristics and early breast cancer related events among
} 652 breast cancer patients

\begin{abstract}
H Jernström ${ }^{*, 1,2}$, E Bågeman', C Rose ${ }^{3}$, P-E Jönsson ${ }^{4,5}$ and C Ingvar ${ }^{6}$
'Department of Oncology, Clinical Sciences, Lund University, Barngatan 2B, Lund SE-22I 85, Sweden; ${ }^{2}$ Faculty of Health and Society, Malmö University, Malmö, Sweden; ${ }^{3}$ Department of Oncology, Lund University Hospital, Lund, Lund SE-22I 85, Sweden; ${ }^{4}$ Department of Surgery, Helsingborg Hospital, Helsingborg SE-25I 87, Sweden; ${ }^{5}$ Department of Clinical Sciences UMAS, Malmö, Sweden; ${ }^{6}$ Department of Surgery, Lund University Hospital, Lund SE22185 , Sweden
\end{abstract}

\begin{abstract}
BACKGROUND: CYP2C8/9 polymorphisms may influence breast cancer-free survival after diagnosis due to their role in the metabolism of tamoxifen, paclitaxel, and other chemotherapy. cytochrome P450 (CYP)2C8/9 metabolise arachidonic acid to epoxyeicosatrienoic acids, which enhance migration and invasion in vitro and promote angiogenesis in vivo. We aimed to investigate the frequency of CYP2C8/9 polymorphisms in relation to breast tumour characteristics and disease-free survival.

METHODS: A prospective series of 652 breast cancer patients from southern Sweden was genotyped for CYP2C8*3, CYP2C8*4, CYP2C9*2, and CYP2C9*3. Blood samples and questionnaires were obtained pre- and postoperatively. Clinical information and tumour characteristics were obtained from patients' charts and pathology reports.

RESULTS: Frequencies of CYP2C8/9 polymorphisms were similar to healthy European populations. Significantly less node involvement $(P=0.002)$ and fewer PR + tumours $(P=0.012)$ were associated with CYP2C8*4. Median follow-up was 25 months and 52 breast cancer-related events were reported. In a multivariate model, CYP2C8/9*3/*I*/*2/*I was the only factor associated with increased risk for early events in 297 tamoxifen-treated, ER-positive patients, adjusted HR 2.54 (95\% Cl I.I I - 5.79). The effect appeared to be driven by CYP2C8*3, adjusted HR 8.56 (95\%Cl I.53-5I.I).

CONCLUSION: Polymorphic variants of CYP2C8/9 may influence breast tumour characteristics and disease-free survival in tamoxifentreated patients.

British Journal of Cancer (2009) I 0 I, I8I7- |823. doi: I0.1038/sj.bjc.6605428 www.bjcancer.com
\end{abstract}

(c) 2009 Cancer Research UK

Keywords: CYP2C8; CYP2C9; polymorphism; disease-free survival; tamoxifen

In Sweden, approximately 7000 women are diagnosed with breast cancer annually and 1500 die of their disease. Up to $25 \%$ of breast cancer patients considered to be at low risk for recurrence, that is, stage-I or II without lymph node involvement, recur within 5 years (Malmström et al, 2001, 2003). Approximately 15\% of all breast cancer patients in Sweden die from their disease within 5 years and $30 \%$ die within 10 years of diagnosis. Adjuvant therapies such as radiation, tamoxifen, aromatase inhibitors (AIs), and chemotherapy improve the prognosis, but also confer a risk of adverse side effects (Early breast cancer trialists' collaborative group, 2005; Forbes et al, 2008). Moreover, many patients receive adjuvant therapy without any impact on survival, as most are already cured by surgery alone or the adjuvant therapy chosen does not work as intended. Markers, which would help to better tailor adjuvant therapy to each patient, are urgently needed.

Several genetic polymorphisms in genes such as cytochromeP450 (CYP)2C8 and CYP2C9, may influence survival after cancer

*Correspondence: Dr H Jernström; E-mail: Helena.Jernstrom@med.lu.se Received 30 June 2009; revised 20 September 2009; accepted 12 October 2009 diagnosis due to their role in the metabolism of various breast cancer drugs, including tamoxifen and chemotherapy (Jin et al, 2005). CYP2C 8 and CYP2C 9 are polymorphic enzymes. CYP2C $8^{*} 3$ and $C Y P 2 C 9^{*} 2$ are the major variant alleles in Caucasian populations (Yasar et al, 2002). Approximately $96 \%$ of subjects with the $C Y P 2 C 8^{\star} 3$ allele also carried a $C Y P 2 C 9^{*} 2$ and $85 \%$ of subjects who had the $C Y P 2 C 9^{\star} 2$ variant also carried a $C Y P 2 C 8^{\star} 3$. CYP2C $8^{*} 3$ is defective in the metabolism of two important CYP2C8 substrates: the anticancer drug paclitaxel (Bahadur et al, 2002) and the physiologically important compound arachidonic acid (AA) (Dai et al, 2001). In addition, variants $C Y P 2 C 8^{\star} 4$ and $C Y P 2 C{ }^{\star} 2$ and $C Y P 2 C 9 * 3$ also have a lower metabolic activity than the wildtype variants (Bahadur et al, 2002; Griskevicius et al, 2003; King et al, 2004; Sandberg et al, 2004).

Arachidonic acid is metabolised via three major pathways: the cyclooxygenase pathway, which produces prostaglandins; the lipoxygenase pathway, and finally the CYP epoxygenase pathway (Belton and Fitzgerald, 2003).

CYP2C8 and 2C9 are CYP epoxygenases, which metabolise AA to epoxyeicosatrienoic acids (EETs) (Zeldin et al, 1995; Michaelis et al, 2005), with the most abundant product being 14,15-EET, which promotes angiogenesis in vivo (Medhora et al, 2003). 
In vitro studies have shown that overexpression of CYP2C9 elicits angiogenesis via activation of the epidermal growth factor receptor (EGFR) (Michaelis et al, 2003). Jiang et al (2007) showed that CYP epoxygenase overexpression enhanced tumour metastasis of MDA-MB-231 human breast carcinoma cells to the lungs of athymic BALB/C mice. Moreover, CYP epoxygenase overexpression or EET treatment markedly enhanced the migration, invasion, and prometastatic gene expression profiles in a variety of cancer cell lines in vitro (Jiang et al, 2007). Functional polymorphisms of CYP2C8 and CYP2C9 may thus be of importance for breast cancer risk, tumour characteristics, and treatment response.

Our study has four interrelated aims: first, to investigate the frequency of the polymorphic variants $C Y P 2 C 8^{\star} 3, C Y P 2 C 8^{\star} 4$, $C Y P 2 C 9^{*} 2$, and $C Y P 2 C 9 * 3$ in a series of breast cancer patients; second, to construct CYP2C8/9 haplotypes; third to determine whether these genetic variants were associated with breast cancer characteristics of prognostic importance; and fourth, to investigate whether any of these genetic variants were associated with early breast cancer-related events.

\section{MATERIALS AND METHODS}

Women assessed preoperatively at the Lund University Hospital and the Helsingborg Hospital, Sweden, for a first breast cancer were invited to take part in an ongoing study regarding genetic and nongenetic factors that could be associated with breast cancer prognosis and treatment response. Patients were included between October 2002 and October 2007 in Lund, and between April 2006 and October 2007 in Helsingborg. Helsingborg is located approximately $50 \mathrm{~km}$ north of Lund. There are nine hospitals in the South Swedish Health Care Region performing breast cancer surgery. The Lund University Hospital catchment area serves almost 300000 inhabitants and the Helsingborg Hospital serves another 250000 inhabitants. Breast cancer patients are not referred to other hospitals for surgery. We, therefore, consider this study population-based.

Women were invited to participate regardless of ethnic background, age, and tumour stage. Patients who had been diagnosed recently and treated for another type of cancer within the past 10 years were not eligible to participate. The study was approved by the Ethics Committee of Lund University. Written informed consents were collected during the preoperative visit at the Department of Surgery at the Lund University Hospital. At the same visit, the research nurse collected blood samples (EDTAplasma and serum) and recorded the time and date when the blood samples were drawn. The blood was centrifuged and separated. Serum, EDTA - plasma, and blood cells were stored at $-70^{\circ} \mathrm{C}$. All samples were labelled with serial codes to enable blinded analyses.

Body weight, height, waist and hip circumferences, and breast volumes were measured at the preoperative visit. All patients filled out a preoperative questionnaire including questions on birth date, coffee consumption, smoking, alcohol intake, use of exogenous hormones and concomitant medications, reproductive history, and family history of cancer. No question enquired about ethnicity. However, the vast majority of women included were ethnic Swedes.

Information including type of surgery, sentinel node biopsy, and axillary node dissection was obtained from each patient's chart. Tumour size, histological type and grade, axillary node involvement, signs of distant metastases, ER, and progesterone receptor (PR) status were obtained from each patient's pathology report.

Histological grade was evaluated according to the procedure of Elston and Ellis (1991). The grading procedure consisted of judgement of tubule formation, nuclear pleomorphism, and mitotic count. The number of mitoses was counted in 10 highpower fields, and the results were adjusted to the area of the microscopic field. Each of the three morphological features, tubules, nuclear pleomorphism, and number of mitoses, was given a score of 1 to 3 points. The overall histological grade was obtained by adding the score of each characteristic, resulting in a possible total score of 3 to 9 points. The histological grade allocation was as follows: grade-1, 3 to 5 points; grade-2, 6 to 7 points; and grade-3, 8 to 9 points.

Oestrogen receptor and PR status was determined by immunohistochemistry using the Dako LSAB kit system (Dako, Glostrup, Denmark) and antibodies M7047 (ER) and M3569 (PR) (Dako) in Lund. In Helsingborg, ER and PR status was determined by immunohistochemistry using the Ventana ultra view kit (760-500) (Ventana, Illkirch, France) and antibodies 790-4324 (ER) (Ventana) and NCL-L-PGR-312 (PR) (NovoCastra, NewCastle, UK). Tumours with more than $10 \%$ positive nuclear staining were considered $\mathrm{ER}+$ or $\mathrm{PR}+$. Receptor-negative tumours had a positive nuclear staining of $10 \%$ or less. All tumours were analysed at the Department of Pathology of Lund University Hospital or Helsingborg Hospital. HER-2/neu status was routinely analysed as of November 2005.

According to data obtained from the Regional Tumor Registry, on June 25,2008 , a total of 6765 primary female breast cancers were registered between October 1, 2002, and October 31, 2007, in the South Swedish Health Care Region. During the same time period, 893 breast tumours were registered in Lund, of which 866 were primary and received surgery. Five hundred and seventeen of them $(60 \%)$ were included in our study. Between April 1, 2006, and October 31, 2007, a total of 330 breast cancers were registered at Helsingborg, of which 298 received surgery, and 136 (46\%) of these were included in our study.

\section{Genetic analyses}

Genomic DNA was extracted from $300 \mu$ l of peripheral blood using the Wizard genomic DNA purification kit (Promega, Madison, WI, USA).

CYP2C $8^{*} 3$ consists of two polymorphisms (G416A) (rs11572080) and (A1196G) (rs10509681). CYP2C8*3 (G416A) (rs11572080) was amplified using PCR primers Fw: $5^{\prime}$-NNCCACCCTTGGTTTTTCT CAACTC- $3^{\prime}$ and Re: $5^{\prime}$-BIOTIN-CCTCACAACCTTGCGGAATTT- $3^{\prime}$ (Biomers, Ulm, Germany), which yield a 105-bp nucleotide sequence. PCR was performed in $25-\mu \mathrm{l}$ reactions using $25 \mathrm{ng}$ DNA, $0.2 \mu \mathrm{m}$ of each primer, $0.2 \mathrm{~mm}$ of each deoxynucleotide (Amersham Biosciences, Buckinghamshire, UK), $1.5 \mathrm{~mm} \mathrm{MgCl}_{2}$ (Applied Biosystems, Foster City, CA, USA), $1 \times$ PCR Gold Buffer (Applied Biosystems), and $0.5 \mathrm{U}$ of AmpliTaq Gold (Applied Biosystems).

CYP2C8*3 (A1196G) (rs10509681) was amplified using PCR primers Fw: $5^{\prime}$-BIOTIN-TTTGTTACTTCCAGGGCACA-3' and Re: 5'-NNAAAGTGGCCAGGGTCAAAG-3' (Biomers), which yield a 101 -bp nucleotide sequence. PCR was performed in $25-\mu \mathrm{l}$ reactions using $25 \mathrm{ng}$ DNA, $0.2 \mu \mathrm{M}$ of each primer, $0.2 \mathrm{~mm}$ of each deoxynucleotide (Amersham Biosciences), $1.5 \mathrm{~mm} \mathrm{MgCl}_{2}$ (Applied Biosystems), $1 \times$ PCR Gold Buffer (Applied Biosystems), and $0.5 \mathrm{U}$ of AmpliTaq Gold (Applied Biosystems). Both SNPs were run for 298 samples with $100 \%$ concordance. We, therefore, genotyped only (rs11572080) for the remaining 354 samples.

CYP2C $8^{\star} 4$ (rs1058930) was amplified using PCR primers Fw: $5^{\prime}$-NNGTTTCCCAGGAACTCACAACAAAG- $3^{\prime}$ and Re: $5^{\prime}$-BIOTINAAGCATTACTGGCCTGATCATTT-3' (Biomers), which yield a 255-bp nucleotide sequence. PCR was performed in $25-\mu \mathrm{l}$ reactions using $25 \mathrm{ng}$ DNA, $0.17 \mu \mathrm{M}$ of each primer, $0.5 \mathrm{~mm}$ of each deoxynucleotide (Amersham Biosciences), $2.0 \mathrm{~mm} \mathrm{MgCl}_{2}$ (Applied Biosystems), $1 \times$ PCR Gold Buffer (Applied Biosystems), and 0.5 U of AmpliTaq Gold (Applied Biosystems).

CYP2C ${ }^{\star} 2$ (rs1799853) was amplified using PCR primers $\mathrm{Fw}$ : $5^{\prime}$-NNGTATTTTGGCCTGAAACCCATA- $3^{\prime}$ and Re: $5^{\prime}$-BIOTIN-CA CCCTTGGTTTTTCTCAACTC-3' (Biomers), which yield a 455-bp nucleotide sequence. PCR was performed in $25-\mu \mathrm{l}$ reactions using $25 \mathrm{ng}$ DNA, $0.2 \mu \mathrm{M}$ of each primer, $0.2 \mathrm{~mm}$ of each deoxynucleotide (Amersham Biosciences), $1.5 \mathrm{mM} \mathrm{MgCl}_{2}$ (Applied Biosystems), $1 \times$ PCR Gold Buffer (Applied Biosystems), and 0.5 U of AmpliTaq Gold (Applied Biosystems). 
CYP2C9*3 (rs1057910) was amplified using PCR primers Fw: $5^{\prime}$-BIOTIN-TGCACGAGGTCCAGAGAT- $3^{\prime}$ and Re: $5^{\prime}$-NNGATACT ATGAATTTGGGACTTC- ${ }^{\prime}$, which yield a 155 -bp nucleotide sequence. PCR was performed in $25-\mu$ l reactions using $25 \mathrm{ng}$ DNA, $0.2 \mu \mathrm{M}$ of each primer, $0.2 \mathrm{~mm}$ of each deoxynucleotide (Amersham Biosciences), $1.5 \mathrm{mM} \mathrm{MgCl}_{2}$ (Applied Biosystems), $1 \times$ PCR Gold Buffer (Applied Biosystems), and 0.5 U of AmpliTaq Gold (Applied Biosystems).

\section{PSQ and sequencing}

The PCR products of $C Y P 2 C 8^{*} 3$ (G416A and A1196G), $C Y P 2 C 8^{\star} 4$, $C Y P 2 C 9^{\star} 2$, and $C Y P 2 C 9{ }^{\star} 3$ were sequenced (PyroGold, Pyrosequencing; Biotage, Uppsala, Sweden) according to the manufacturer's instructions and run on pyrosequencing (PSQ) HS 96A. The following PSQ primers were used: CYP2C8*3(G416A)_PSQ, $5^{\prime}$-CGGTCCTCAATGCTC-3'; CYP2C $8^{*} 3(\mathrm{~A} 1196 \mathrm{G})$ PSQ, $5^{\prime}$-ATTTG GATTAGGAAATTCT $-3^{\prime}$; CYP2C $8^{\star} 4$ _PSQ, $5^{\prime}$-CAATCCTCGGGACT TT-3'; CYP2C ${ }^{*} 2$ 2_PSQ, $5^{\prime}$-GGGAAGAGGAGCATTGAGGAC- ${ }^{\prime}$; and CYP2C $9^{*} 3$ PSQ, $5^{\prime}-$ TGGTGGGGAGAAGGTC- $3^{\prime}$ (Biomers). Results were analysed using the inbuilt software programme on PSQ HS 96A. For quality control, every fourth sample was run in duplicate in separate PCR and PSQ reactions.

All different genotypes found in the PSQ reaction were confirmed by sequencing (Big Dye, Terminator Cycle Sequencing; Applied Biosystems) according to the manufacturer's instructions and run on an ABI 3100 Genetic Analyzer (Applied Biosystems). In April 2006, the system was upgraded to an ABI Prism 3130xl Genetic Analyzer (Applied Biosystems). Results were analysed using the Sequencing Analysis software (Applied Biosystems) and evaluated using the Sequencher software (Gene Codes Corporation) current version 4.5 .

Validation Validation was performed with separate PCR and sequencing reactions.

CYP2C $8^{\star 3}$ : Four hundred and twenty-two samples have been validated and the concordance rate was $100 \%$.

$C Y P 2 C 8^{\star} 4$ : One hundred and ninety-two samples have been validated and the concordance rate was $100 \%$.

$C Y P 2 C 9^{\star} 2$ : One hundred and eighty-one samples have been validated and the concordance rate was $97.2 \%$.

A homozygote $C Y P 2 C 9{ }^{\star} 2$ reference sample was sometimes analysed with the PSQ software as a heterozygote instead of a homozygote. We, therefore, re-evaluated all the heterozygotes to make sure they were not in fact homozygotes, and they were not.

CYP2C9*3: One hundred and eighty-two samples have been validated and the concordance rate was $100 \%$.

\section{Statistical analyses}

The statistical software PASW 17.0 was used. Tumour characteristics were compared between different genotypes using Student's $t$-test for continuous variables (age and tumour size) and $\chi^{2}$-test for categorical variables. Mann-Whitney $U$-test was used for tumour size since this variable was not normally distributed. Tumour size was transformed using natural logarithm to obtain a better distribution for use in the multivariate linear regression models. Breast cancer-free survival rates in relation to different genotypes were assessed using Kaplan-Meier log-rank test and Cox regression models. A $P$-value less than 0.05 was considered significant. All $P$-values were two-sided. Nominal $P$-values are presented without adjustment for multiple testing.

\section{RESULTS}

The characteristics of the women are presented in Table 1. Of the patients, 517 were included in Lund and 135 in Helsingborg. Age at diagnosis and all tumour characteristics were comparable between
Table I Preoperative characteristics of the 652 patients

\begin{tabular}{lccc}
\hline & \multicolumn{3}{c}{ All patients } \\
\cline { 2 - 4 } & Median or \% & IQR & Missing \\
\hline Age at diagnosis (years) & 59.6 & $50.7-67.0$ & 0 \\
Height $(\mathrm{cm})$ & 165 & $162-170$ & 1 \\
Weight $(\mathrm{kg})$ & 68 & $61-76$ & 1 \\
Body mass index (BMI) $\left(\mathrm{kg} \mathrm{m}^{-2}\right)$ & 24.6 & $22.3-27.7$ & 2 \\
Waist-to-hip ratio $(\mathrm{WHR})$ & 0.83 & $0.78-0.88$ & 4 \\
Total breast volume $\left(\mathrm{cm}^{3}\right)$ & 1000 & $700-1600$ & 9 \\
Age at menarche (years) & 13 & $12-14$ & 5 \\
Premenopausal & $24.5 \%$ & & 4 \\
Age at menopause & 50 & $47-52$ & 192 \\
Age at first full-term pregnancy & 24 & $21-28$ & 96 \\
Parity & 2 & $1-3$ & 0 \\
Ever oral contraceptive use & $70.1 \%$ & & 0 \\
Ever hormone replacement therapy use & $45.6 \%$ & & 1 \\
Abstainer of alcohol (\%) & $12.1 \%$ & & 1 \\
Current smoker (\%) & $22.0 \%$ & & 1 \\
Daily coffee consumption (cups) & 3 & $2-4$ & 2 \\
I $^{\circ}$ relative with breast cancer & $19.2 \%$ & & 21 \\
\hline
\end{tabular}

Abbreviation: $I Q R=$ interquartile range. ${ }^{a}$ Among parous women only.

Table $2(a-c)$ The relationship between CYP2C8 and CYP2C9 genotypes in the breast cancer patient group

\begin{tabular}{lcccc}
\hline (a) & CYP2C8*1/*1 & CYP2C8*1/*4 & CYP2C8*4 $1 * 4$ & $n$ \\
CYP2C8*1/*1 & 445 & 76 & 3 & 524 \\
CYP2C8*11*3 & 116 & 5 & 0 & 121 \\
CYP2C8*3/*3 & 7 & 0 & 0 & 7 \\
$n$ & 568 & 81 & 3 & 652 \\
& & & & \\
(b) & CYP2C9*1/*1 & CYP2C9*1/*3 & CYP2C9*3/*3 & $n$ \\
CYP2C9*1/*1 & 438 & 67 & 2 & 507 \\
CYP2C9*1/*2 & 124 & 11 & 0 & 135 \\
CYP2C9*21*2 & 8 & 0 & 0 & 8 \\
$n$ & 570 & 78 & 2 & 650 \\
& & & & \\
(c) & CYP2C9*1/*1 & CYP2C9*1/*2 & CYP2C9*21*2 & $n$ \\
CYP2C8*1/*1 & 498 & 25 & 1 & 524 \\
CYP2C8*1/*3 & 9 & 110 & 1 & 120 \\
CYP2C8*3/*3 & 0 & 1 & 6 & 7 \\
$n$ & 507 & 136 & 8 & 652 \\
\hline
\end{tabular}

Abbreviation: CYP = cytochrome P450. Table 2a shows linkage disequilibrium (LD) between the CYP2C8*3 and CYP2C8*4 genotypes among the 652 breast cancer patients included. Table $2 b$ shows LD between the CYP2C9*2 and CYP2C9*3 genotypes. Table $2 c$ confirms the previously reported imperfect LD between CYP2C8*3 and CYP2C9*2. Genotype data on CYP2C9*2 were missing for one woman and CYP2C9*3 genotype data were missing for another woman.

patients from the two hospitals, except for histological grade, which was higher in Helsingborg patients $\left(\chi^{2}\right.$-test $\left.P<0.001\right)$.

The frequencies of $C Y P 2 C 8$ and $C Y P 2 C 9$ polymorphisms are presented in Table $2 \mathrm{a}-\mathrm{c}$. $C Y P 2 C 8^{\star} 3$ and $C Y P 2 C 8^{\star} 4$ were in linkage disequilibrium (LD) and appeared not to be present on the same allele (Table 2a). Similarly, $C Y P 2 C 9^{*} 2$ and $C Y P 2 C 9 * 3$ were in LD and appeared to be mutually exclusive (Table $2 \mathrm{~b}$ ). As previously reported, $C Y P 2 C 8^{*} 3$ and $C Y P 2 C 9^{*} 2$ were highly, but not perfectly, linked (Table $2 \mathrm{c}$ ). None of the polymorphisms differed significantly in frequency between patients from the two hospitals.

Based on the above information we constructed the most likely haplotypes of CYP2C8/9 (Table 3). Six haplotypes were found in this patient population. More than half of the patients $(55.5 \%)$ carried two copies of alleles with wild-type SNPs in all four positions. Another $37.7 \%$ carried one such haplotype. The second most common haplotype was the combination of $C Y P 2 C 8^{*} 3$ and $C Y P 2 C{ }^{\star} 2$, and was present in $17.9 \%$ of patients. $C Y P 2 C 8^{\star} 4$ 
Table 3 shows the frequencies of the most likely CYP2C8/9 haplotypes sorted according to their frequency among the breast cancer patients

\begin{tabular}{lcccc}
\hline & No allele & One allele & Two alleles & Missing \\
\hline CYP2C8/9*1/*1/*1/*| & $42(6.4)$ & $246(37.7)$ & $362(55.5)$ & $2(0.3)$ \\
CYP2C8/9*3/*1/*2/*| & $533(81.7)$ & $111(17.0)$ & $6(0.9)$ & $2(0.3)$ \\
CYP2C8/9*1/*4/*1/*| & $566(86.8)$ & $81(12.4)$ & $3(0.5)$ & $2(0.3)$ \\
CYP2C8/9*1/*1/*1/*3 & $570(87.4)$ & $78(12.0)$ & $2(0.3)$ & $2(0.3)$ \\
CYP2C8/9*1/*1/*2/*1 & $623(95.6)$ & $26(4.0)$ & $1(0.2)$ & $2(0.3)$ \\
CYP2C8/9*3/*1/*1/*| & $640(98.2)$ & $10(1.5)$ & $0(0.0)$ & $2(0.3)$ \\
\hline
\end{tabular}

Abbreviation: CYP $=$ cytochrome P450. These were constructed based on the information obtained from Tables $2 a-c$.

Table 4 Characteristics of the 612 tumours from the patients not treated with preoperative interstitial laser thermo therapy $(n=1 \mid$ and I uncertain) or neoadjuvant therapy $(n=28)$ in this study

\begin{tabular}{|c|c|c|}
\hline & $n(\%)$ & Any CYP2C $8 * 4$ allele (\%) \\
\hline \multicolumn{3}{|c|}{ Invasive tumour size } \\
\hline $\mathrm{P}_{\text {is }}$ & $14(2.3)$ & 28.6 \\
\hline pTI & $432(70.6)$ & 12.0 \\
\hline PT2 & $152(24.8)$ & 13.8 \\
\hline pT3 & $12(12.0)$ & 8.3 \\
\hline pT4 & I (0.2) & 0 \\
\hline Missing & $3(0.5)$ & \\
\hline \multicolumn{3}{|c|}{ Axillary lymph node involvement } \\
\hline $\mathrm{pN}-$ & $389(63.8)$ & 15.9 \\
\hline $\mathrm{pN}+$ & $220(35.9)$ & 7.3 \\
\hline Missing & $3(0.5)$ & \\
\hline \multicolumn{3}{|c|}{ Histological grade } \\
\hline Grade I & $156(25.5)$ & 9.3 \\
\hline Grade 2 & $312(51.0)$ & 12.2 \\
\hline Grade 3 & $142(23.2)$ & 16.9 \\
\hline Missing & $3(0.5)$ & \\
\hline \multicolumn{3}{|c|}{ Hormone receptor status } \\
\hline $\mathrm{ER}+/ \mathrm{PR}+$ & $41 \mid(67.2)$ & 10.2 \\
\hline $\mathrm{ER}+/ \mathrm{PR}-$ & $111(18.1)$ & 16.2 \\
\hline ER-/PR- & $72(11.8)$ & 19.4 \\
\hline ER-/PR+ & $4(0.7)$ & 0 \\
\hline Missing & $13(2.1)$ & \\
\hline
\end{tabular}

Abbreviations: $\mathrm{CYP}=$ cytochrome $\mathrm{P} 450$; $E R=$ oestrogen receptor, $\mathrm{PR}=$ progesterone receptor. The CYP2C8*4 allele was the only genotype that was associated with tumour characteristics. The percentage of patients with at least one CYP2C8*4 allele is indicated in relation to the tumour characteristics. *Large and inflammatory tumours were treated by neoadjuvant therapy; therefore there is no information presented on these tumours.

appeared only on a haplotype, with wild type SNPs in the remaining three positions, and was present in nearly $13 \%$ of the patients. CYP2C $9 * 3$ in combination with wild-type SNPs in the remaining three positions was present in over $12 \%$ of the patients. Other combinations were rare or did not exist.

\section{Tumour characteristics in relation to polymorphisms in CYP2C8 and CYP2C9}

Patients without preoperative treatment and at least one copy of $C Y P 2 C 8^{\star} 3, C Y P 2 C{ }^{\star} 2$, or $C Y P 2 C{ }^{*} 3$ did not significantly differ with respect to age at diagnosis, invasive tumour size, axillary node status, histological grade, and ER or PR status when compared with the wild-type for each SNP. However, carrying at least one copy of $C Y P 2 C 8^{\star} 4$ was associated with a significantly lower frequency of axillary lymph node involvement ( $21 \%$ versus $38 \%$;
$P=0.002)$ in spite of a lower frequency of PR-positive tumours (57\% versus $71 \% ; P=0.012)$ and similar tumour sizes compared with patients without this SNP (Table 4).

\section{Haplotypes of CYP2C8/9 in relation to tumour characteristics}

Only the haplotype allele containing the $C Y P 2 C 8^{\star} 4$ was associated with the tumour characteristics as presented above.

\section{Factors associated with axillary lymph node status}

Since women with the $C Y P 2 C 8^{\star} 4$ appeared to have lower risk for lymph node involvement, we performed multivariate logistic regression analyses to elucidate which factors were associated with axillary lymph node status. Patients with invasive tumours, who had not received neo-adjuvant treatment or interstitial laser thermotherapy, were included in the analyses.

Only increasing tumour size was associated with axillary lymph node spread $(P<0.0001)$, adjusted for age at diagnosis, histological grade, and ER and PR status. We then added the haplotype with the CYP2C ${ }^{\star} 4$ allele to the model. The number of $C Y P 2 C 8 / 9{ }^{*} 1{ }^{\star} 4$ / ${ }^{*} 1 /{ }^{*} 1$ copies was significantly associated with a decreased frequency for axillary lymph node involvement (odds ratio (OR) 0.40 ; 95\% Confidence interval (CI) $0.22-0.74 ; P=0.003$ ), adjusted for tumour size, histological grade, age at diagnosis, and ER and PR status.

In women with invasive tumour sizes of $20 \mathrm{~mm}$ or less, the CYP2C $8 / 9{ }^{*} 1 /{ }^{*} 4 /{ }^{*} 1 /{ }^{*} 1$ haplotype allele was not associated with lymph node status. Conversely, in women with tumours that were $21 \mathrm{~mm}$ or larger, each $C Y P 2 C 8 / 9{ }^{*} 1{ }^{*} 4 /{ }^{*} 1 /{ }^{*} 1$ allele was associated with significantly lower risk for lymph node involvement (OR 0.18 , $95 \%$ CI $0.06-0.54 ; P=0.002$ ), while each copy of the CYP2C8/9 $* 3$ / ${ }^{*} 1 /{ }^{*} 2 /{ }^{*} 1$ allele was associated with a more than doubled risk of lymph node involvement (OR 2.53, 95\% CI 0.97-6.64; $P=0.06$ ), adjusted for tumour size, histological grade, age at diagnosis, and ER and PR status. The associations between the CYP2C $8 / 9{ }^{*} 1 /{ }^{*} 4 /$ ${ }^{*} 1{ }^{*} 1$ haplotype and $C Y P 2 C 8 / 9{ }^{*} 3 /{ }^{*} 1{ }^{*} 2 /{ }^{*} 1$ haplotypes and lymph node involvement was different depending on the invasive tumour size $\left(\exp (\beta)=0.33 ; P_{\text {interaction }}=0.10\right.$ and $\exp (\beta)=3.2$; $P_{\text {interaction }}=0.040$, respectively, when entered into the same model). The effects were somewhat stronger when the interaction terms were entered individually $\left(\exp (\beta)=0.33 ; P_{\text {interaction }}=0.066\right.$ for $C Y P 2 C 8 / 9{ }^{*} 1 /{ }^{*} 4{ }^{*} 1 /{ }^{*} 1$ and $\exp (\beta)=3.4 ; P_{\text {interaction }}=0.028$ for $C Y P 2 C 8 / 9{ }^{*} 3 /{ }^{*} 1{ }^{*} 2 /{ }^{*} 1$ ). Since $C Y P 2 C 8^{*} 3$ and $C Y P 2 C 9^{\star} 2$ are not in perfect LD, we also examined each SNP separately in women with tumours $21 \mathrm{~mm}$ or larger. For each copy of the CYP2C $8 * 3$ allele, the adjusted odds for nodal involvement was 2.74 (95\%CI $1.16-$ $6.51 ; P=0.022)$. For each copy of $C Y P 2 C 9^{\star} 2$, the adjusted OR was $2.81(95 \%$ CI $1.18-6.67 ; P=0.020)$.

\section{Breast cancer-related events}

We then investigated the association between CYP2C8/9 haplotypes in relation to early breast cancer events (local, regional, new breast cancer, distant metastases, or death from breast cancer) by December 2008. The median follow-up time is now 25 months (range 0-62 months). During this period, 52 breast cancer-related events were reported in women with primary invasive breast cancer, excluding four women who were found to have distant metastases on the postoperative metastatic screen. Seven of these women had received some form of neoadjuvant therapy, three women had received preoperative interstitial laser thermotherapy, 14 women had received postoperative polychemotherapy, 23 women had received tamoxifen, and eight women had received an aromatase inhibitor prior to recurrence (some women received more than one adjuvant treatment). The CYP2C8 enzyme is involved in paclitaxel metabolism, but only one woman with a 


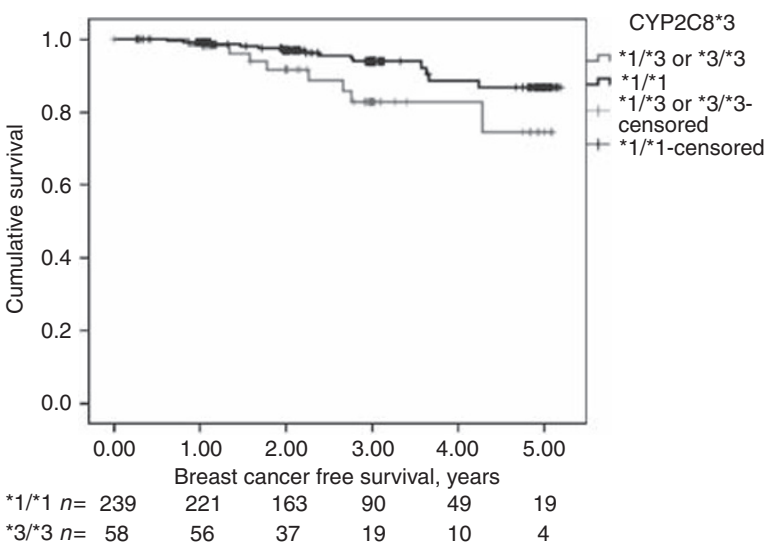

Figure I The figure shows that having at least one copy of the CYP2C8*3 allele conferred an increased risk for an early breast cancerrelated event in tamoxifen-treated women with invasive ER-positive cancers (log rank 4.47; I $d f ; P=0.034)$. HR 9.10 (95\% Cl I.39-59.6; $P=0.021$ ), adjusted for invasive tumour size, age, $P R$, histological grade, axillary lymph node status, CYP2C8*4, CYP2C9*2, and CYP2C9*3. The number of patients at each time point is indicated.

breast cancer-related event had been treated with a paclitaxelbased regimen and four other women with events had received a docetaxel-based regimen as neoadjuvant treatment.

The increasing number of $C Y P 2 C 8^{*} 3 /{ }^{*} 1 /{ }^{*} 2 /{ }^{*} 1$ alleles was associated with shorter disease-free survival in 297 ER-positive patients with invasive tumours who had received tamoxifen prior to the last follow-up or event (log rank 6.36; $1 \mathrm{df} ; P=0.012)$, HR 2.54 (95\% CI 1.11-5.79; $P=0.027$ ), adjusted for age, tumour size, axillary lymph node status, PR status, histological grade, and other haplotypes. None of the other factors adjusted for in the model were significantly associated with early events.

Since there was a high degree of LD between $C Y P 2 C 8^{\star} 3$ and $C Y P 2 C 9^{\star} 2$, we also examined the risk of event in women the $C Y P 2 C 8^{\star} 3$ allele. The results were stronger $(\log$ rank $8.16 ; 1 \mathrm{df}$; $P=0.004)$, adjusted HR 8.56 (95\% CI $1.53-51.1 ; P=0.015)$ per copy. Since there were only few women who were homozygous for $C Y P 2 C 8^{\star} 3$, we also examined the $\mathrm{HR}$ for women with any $C Y P 2 C 8^{*} 3$ allele (log rank $4.471 \mathrm{df} ; P=0.034$ ), adjusted HR 9.10 (95\%CI 1.39-59.6; $P=0.021$ ) (Figure 1). There was no significant effect of carrying at least one $C Y P 2 C 9^{\star} 2$, but it went in the opposite direction, adjusted HR $0.22(95 \% \mathrm{CI} 0.33-1.51 ; P=0.12)$.

\section{DISCUSSION}

This study is, to our knowledge, the first to have constructed $C Y P 2 C 8 / 9$ haplotypes including the $C Y P 2 C 8^{\star} 4$ polymorphism and to have shown that this polymorphism is unlikely to be present on the same allele as $C Y P 2 C 8^{\star 3}$ in a Swedish population. A recent paper on a small Spanish population reported a similar finding (Dorado et al, 2008), but the frequency of $C Y P 2 C 8^{\star} 4$ was much lower in that study. The frequencies of $C Y P 2 C 8^{*} 3$ and $C Y P 2 C 8^{\star} 4$ were similar to those reported in the HapMap project for European populations (NCBI SNP homepage, 2008), and the frequencies of the $C Y P 2 C 9{ }^{\star} 2$ and $C Y P 2 C 9{ }^{\star} 3$ were in line with those reported by Yasar et al (1999) from a Swedish population of 430 unrelated healthy people.

This is the first study to report an association between decreased odds for lymph node involvement and $C Y P 2 C 8^{\star} 4$ and an over twofold increased odds for lymph node involvement among CYP2C $8 / 9{ }^{*} 3 /{ }^{*} 1 /{ }^{*} /{ }^{*} 1$ carriers with invasive tumour sizes over $20 \mathrm{~mm}$. CYP $2 C 8^{\star} 3$ and $C Y P 2 C 8^{\star} 4$ have both been reported to have lower metabolic activity than the wild type (Bahadur et al, 2002), but the associations between these polymorphisms and axillary nodal involvement went in opposite directions in the current study. Since $C Y P 2 C 8^{\star} 3$ was in strong LD with $C Y P 2 C 9{ }^{\star} 2$, it is likely that the association between $C Y P 2 C 8^{*} 3$ and nodal status is actually reflecting the association between the $C Y P 2 C 9^{\star} 2$ polymorphism and nodal status.

We found that an increasing number of $C Y P 2 C 8 / 9{ }^{*} 3 /{ }^{*} 1 /{ }^{*} 2 /{ }^{*} 1$ haplotype alleles and especially $C Y P 2 C 8^{\star} 3$ alleles was associated with increased hazard of early breast cancer-related events in tamoxifen-treated patients. Tamoxifen is a moderate CYP2C8 inhibitor (Walsky et al, 2005), a CYP2C9 substrate (Jin et al, 2005), and significantly inhibits CYP2C9 activity in breast cancer patients (Boruban et al, 2006). CYP2C9 is involved in tamoxifen activation, although neither $C Y P 2 C 9{ }^{\star} 2$ nor $C Y P 2 C 9 * 3$, which have lower activity than the wild type, were significantly associated with the levels of the potent tamoxifen metabolite endoxifen in one study (Jin et al, 2005). The effect of CYP2C8 polymorphisms on endoxifen levels has, to our knowledge, not been investigated. Since the LD between $C Y P 2 C 8^{*} 3$ and $C Y P 2 C{ }^{*} 2$ was incomplete, we also examined the effect of each SNP separately in the model, and while $C Y P 2 C 8^{\star 3}$ was associated with significant increased hazard of early breast cancer-related events, $C Y P 2 C 9^{*} 2$ was associated with non-significant decreased hazard. If our finding is replicated, the $C Y P 2 C 8^{\star} 3$ may be used to identify patients who may recur early when treated with tamoxifen and who should be offered additional or different treatment.

Currently, no genotype data are used prior to selection of tamoxifen or aromatase inhibitors for breast cancer patients with ER-positive tumours warranting adjuvant endocrine treatment. CYP2D6 has been shown to significantly affect the levels of endoxifen and clinical outcome after tamoxifen treatment (Jin et al, 2005; Goetz et al, 2008). To our knowledge there is no association between CYP2D6 and CYP2C8/9, and these genes are located on different chromosomes. It is, therefore, unlikely that the increased risk for early recurrences observed in $C Y P 2 C 8^{*} 3$ carriers would be explained by CYP2D6 polymorphisms. Schroth et al. studied CYP2D6, CYP2C19, CYP3A5, CYP2B6, and CYP2C9 in tamoxifen-treated women. They reported that the $C Y P 2 C 19 * 17$ allele partly compensates for non-functioning CYP2D6 alleles and showed that carriers of one CYP2D6-null allele could be further stratified according to their $C Y P 2 C 19^{\star} 17$ genotype with respect to tamoxifen response (Schroth et al, 2007). The genotypes of $C Y P 3 A 5, C Y P 2 B 6$, and CYP2C9 were not significantly associated with tamoxifen response, which is in line with our finding with respect to $C Y P 2 C 9^{\star} 2$ and $C Y P 2 C 9^{\star} 3$, but they did not examine CYP2C8.

The St Gallen guidelines recommend that extensive peritumoral vascular invasion be used as a prognostic factor (Goldhirsch et al, 2007). The degree of angiogenesis is not yet routinely evaluated in the clinical setting in Sweden, and we could, therefore, not evaluate whether there was any association between peritumoral vascular invasion and CYP2C8/9 haplotypes. It is plausible that we could have found an association, since CYP2C9-derived EETs stimulate angiogenesis (Michaelis et al, 2003). CYP2C9-derived EETs do so by a mechanism involving activation of the EGFR (Michaelis et al, 2003). One study reported high expression of EGFR to be inversely correlated with nodal metastases and shorter, distant disease-free survival in a group of breast cancer patients who had received 2 years of adjuvant tamoxifen treatment (Dihge et al, 2008). This is not fully compatible with our finding, as we found both a higher frequency of nodal involvement with the CYP2C8/9 ${ }^{*} 3 /{ }^{*} 1{ }^{*} 2 /{ }^{*} 1$ genotype (in tumours larger than $20 \mathrm{~mm}$ ) and a higher risk of any type of breast cancer recurrence, especially in women treated with tamoxifen. In small tumours, angiogenesis is also a predictor of nodal status (Arisio et al, 2000), and it is thus possible that women with the CYP2C8/9 ${ }^{*} 3 /{ }^{*} 1 /{ }^{*} 2 /{ }^{*} 1$ genotype have tumours that are more likely to metastasise through increased angiogenesis. 
The enzyme activity of CYP2C8 and CYP2C9 is not only determined by polymorphic variants, but also by use of CYP2C8and CYP2C9-inhibiting compounds, including several drugs, as reviewed by Ingelman-Sundberg et al (2007). In the present study we enquired only about the use of all concomitant medications during the past week and lack information on long-term use of any of the medications. However, this information is not relevant in relation to tumour characteristics as the tumours were formed many years prior to diagnosis.

HER-2/neu status was not analysed routinely before November 2005, and we have therefore not been able to evaluate the correlation between HER-2 overamplification and CYP2C8/9 haplotypes. Histological grade was assessed according to the procedure of Elston and Ellis (1991). In the current study histological grade was not associated with early recurrences in either group (data not shown), but the median follow-up time is still short.

Our material consisted of a series of primary breast cancer patients, where the only exclusion criteria were any previous breast cancer diagnosis and other cancer diagnosed within the past 10 years. Approximately $60 \%$ of the patients operated on in Lund and $46 \%$ of the patients operated on in Helsingborg during the study's enrolment period were included. Our sample from Lund was similar to all patients from Lund with respect to age and ER and PR status. The patients from Helsingborg were somewhat older and had fewer PR-positive tumours as compared with the region as a whole, while the subset of patients who were included in this study was comparable to those included from Lund and the whole South Swedish region with respect to age and hormone-receptor status. There are several potential explanations for why receptor status may be different in Helsingborg patients. The patients in Helsingborg are somewhat older and different sets of antibodies are used at different Departments of pathology. ER and PR status was independently re-assessed by 22 pathologists from nine hospitals and the kappa values were 0.78 for ER and 0.72 for PR in 2003 (Chebil et al, 2003). Provided that these markers are used for selection of breast cancer treatment, quality assurance is ongoing. The frequency of HRT use may also differ between the two cities and HRT treatment is associated with a higher frequency of ER-positive tumours (Glass et al, 2007). As patients who were included did not differ with respect to ER, PR, or prior HRT use, we were unable to explain why patients from Helsingborg in general would have fewer PR-positive tumours.

\section{REFERENCES}

Arisio R, Sapino A, Cassoni P, Accinelli G, Cuccorese MC, Mano MP, Bussolati G (2000) What modifies the relation between tumour size and lymph node metastases in T1 breast carcinomas? J Clin Pathol 53: $846-850$

Bahadur N, Leathart JB, Mutch E, Steimel-Crespi D, Dunn SA, Gilissen R, Houdt JV, Hendrickx J, Mannens G, Bohets H, Williams FM, Armstrong M, Crespi CL, Daly AK (2002) CYP2C8 polymorphisms in Caucasians and their relationship with paclitaxel 6alpha-hydroxylase activity in human liver microsomes. Biochem Pharmacol 64: 1579-1589

Belton O, Fitzgerald DJ (2003) Cyclooxygenase isoforms and atherosclerosis. Expert Rev Mol Med 5: 1-18

Boruban MC, Yasar U, Babaoglu MO, Sencan O, Bozkurt A (2006) Tamoxifen inhibits cytochrome P450 2C9 activity in breast cancer patients. J Chemother 18: $421-424$

Chebil G, Bendahl PO, Ferno M (2003) Estrogen and progesterone receptor assay in paraffin-embedded breast cancer-reproducibility of assessment. Acta Oncol 42: 43-47

Dai D, Zeldin DC, Blaisdell JA, Chanas B, Coulter SJ, Ghanayem BI, Goldstein JA (2001) Polymorphisms in human CYP2C8 decrease metabolism of the anticancer drug paclitaxel and arachidonic acid. Pharmacogenetics 11: 597-607

Dihge L, Bendahl PO, Grabau D, Isola J, Lovgren K, Ryden L, Ferno M (2008) Epidermal growth factor receptor (EGFR) and the estrogen
In conclusion, we found that the frequencies of $C Y P 2 C 8^{\star} 3$ and $C Y P 2 C 8^{*} 4$, and $C Y P 2 C 9^{*} 2$ and $C Y P 2 C 9^{*} 3$ were comparable to those of healthy European populations. Each copy of the CYP2C8/9 ${ }^{*} 1 /{ }^{*} 4 /{ }^{*} 1{ }^{*} 1$ allele was associated with significantly lower risk for nodal involvement, while each copy of the CYP2C $8 / 9{ }^{*} 3 /{ }^{*} 1 /{ }^{*} 2 /{ }^{*} 1$ allele was associated with increased risk for nodal involvement in tumours larger than $20 \mathrm{~mm}$. Moreover, the $C Y P 2 C 8^{\star} 3$ allele was associated with early breast cancer-related events in women treated with tamoxifen. Since this is the first study reporting an association between $C Y P 2 C 8$ and tamoxifen response, and the median follow-up time is still short, the finding warrants confirmation. If confirmed, it is possible that $C Y P 2 C 8^{\star} 3$ can be used as a genetic marker for prediction of treatment response to tamoxifen.

\section{ACKNOWLEDGEMENTS}

We thank the participants of this study. We also thank the following research nurses for data collection: Annette Möller, Karin Henriksson, Anna Weddig, Linda Ågren, Ulrika Midelund, Arnhild Nilsson, and Karina Sandström. We would like to acknowledge Maj-Britt Hedenblad and Sol-Britt Olsson for data entry and DNA-extraction. We thank Dr Eric $\mathrm{T}$ Dryver for proofreading the paper. This study was supported by grants from The Swedish Cancer Society, The Mrs Berta Kamprad Cancer Foundation, Lund University Hospital Fund, The Crafoord Foundation, The G Nilsson Foundation, The Swedish Research Council (K2001-27GX-14120-01A and K2008-68X-20802-01-3), The GA's Donation for Breast Cancer Research, the 1049 Fund at the Lund Oncology Clinic, the Region Skane ALF, the Medical Faculty of Lund University, and an unrestricted grant by Novartis. Erika Bågeman's position was supported by the by grants from The Swedish Cancer Society, The G Nilsson Foundation, The Swedish Research Council (K2001-27GX-1412001A), and the Medical Faculty of Lund University. Drs Christian Ingvar, Carsten Rose, and Per-Ebbe Jönsson were financially supported through their clinical positions. Dr Helena Jernström's position was supported by The Swedish Research Council (K200227GP-14104-02B), the Medical Faculty of Lund University, The Crafoord Foundation, and the Faculty of Health and Society of Malmö University. receptor modulator amplified in breast cancer (AIB1) for predicting clinical outcome after adjuvant tamoxifen in breast cancer. Breast Cancer Res Treat 109: 255-262

Dorado P, Cavaco I, Caceres MC, Piedade R, Ribeiro V, Llerena A (2008) Relationship between CYP2C8 genotypes and diclofenac 5-hydroxylation in healthy Spanish volunteers. Eur J Clin Pharmacol 64: 967-970

Early breast cancer trialists' collaborative group (2005) Effects of chemotherapy and hormonal therapy for early breast cancer on recurrence and 15-year survival: an overview of the randomised trials. Lancet 365: $1687-1717$

Elston CW, Ellis IO (1991) Pathological prognostic factors in breast cancer. I. The value of histological grade in breast cancer: experience from a large study with long-term follow-up. Histopathology 19: 403-410

Forbes JF, Cuzick J, Buzdar A, Howell A, Tobias JS, Baum M (2008) Effect of anastrozole and tamoxifen as adjuvant treatment for early-stage breast cancer: 100-month analysis of the ATAC trial. Lancet Oncol 9: 45-53

Glass AG, Lacey Jr JV, Carreon JD, Hoover RN (2007) Breast cancer incidence, 1980-2006: combined roles of menopausal hormone therapy, screening mammography, and estrogen receptor status. J Natl Cancer Inst 99: $1152-1161$

Goetz MP, Kamal A, Ames MM (2008) Tamoxifen pharmacogenomics: the role of CYP2D6 as a predictor of drug response. Clin Pharmacol Ther 83: $160-166$ 
Goldhirsch A, Wood WC, Gelber RD, Coates AS, Thurlimann B, Senn HJ (2007) Progress and promise: highlights of the international expert consensus on the primary therapy of early breast cancer 2007. Ann Oncol 18: $1133-1144$

Griskevicius L, Yasar U, Sandberg M, Hidestrand M, Eliasson E, Tybring G, Hassan M, Dahl ML (2003) Bioactivation of cyclophosphamide: the role of polymorphic CYP2C enzymes. Eur J Clin Pharmacol 59: 103-109

Ingelman-Sundberg M, Sim SC, Gomez A, Rodriguez-Antona C (2007) Influence of cytochrome $\mathrm{P} 450$ polymorphisms on drug therapies: pharmacogenetic, pharmacoepigenetic and clinical aspects. Pharmacol Ther 116: $496-526$

Jiang JG, Ning YG, Chen C, Ma D, Liu ZJ, Yang S, Zhou J, Xiao X, Zhang XA, Edin ML, Card JW, Wang J, Zeldin DC, Wang DW (2007) Cytochrome P450 epoxygenase promotes human cancer metastasis. Cancer Res 67: 6665-6674

Jin Y, Desta Z, Stearns V, Ward B, Ho H, Lee KH, Skaar T, Storniolo AM, Li L, Araba A, Blanchard R, Nguyen A, Ullmer L, Hayden J, Lemler S, Weinshilboum RM, Rae JM, Hayes DF, Flockhart DA (2005) CYP2D6 genotype, antidepressant use, and tamoxifen metabolism during adjuvant breast cancer treatment. J Natl Cancer Inst 97: 30 - 39

King BP, Khan TI, Aithal GP, Kamali F, Daly AK (2004) Upstream and coding region CYP2C9 polymorphisms: correlation with warfarin dose and metabolism. Pharmacogenetics 14: $813-822$

Malmström P, Bendahl PO, Boiesen P, Brünner N, Idvall I, Fernö M, South Sweden Breast Cancer Group (2001) S-phase fraction and urokinase plasminogen activator are better markers for distant recurrences than Nottingham Prognostic Index and histologic grade in a prospective study of premenopausal lymph node-negative breast cancer. J Clin Oncol 19: $2010-2019$

Malmström P, Holmberg L, Anderson H, Mattsson J, Jönsson PE, TennvallNittby L, Balldin G, Loven L, Svensson JH, Ingvar C, Möller T, Holmberg E, Wallgren A, Swedish Breast Cancer Group (2003) Breast conservation surgery, with and without radiotherapy, in women with lymph nodenegative breast cancer: a randomised clinical trial in a population with access to public mammography screening. Eur J Cancer 39: $1690-1697$
Medhora M, Daniels J, Mundey K, Fisslthaler B, Busse R, Jacobs ER, Harder DR (2003) Epoxygenase-driven angiogenesis in human lung microvascular endothelial cells. Am J Physiol Heart Circ Physiol 284: $\mathrm{H} 215$ - H224

Michaelis UR, Fisslthaler B, Barbosa-Sicard E, Falck JR, Fleming I, Busse R (2005) Cytochrome P450 epoxygenases 2C8 and 2C9 are implicated in hypoxia-induced endothelial cell migration and angiogenesis. J Cell Sci 118: $5489-5498$

Michaelis UR, Fisslthaler B, Medhora M, Harder D, Fleming I, Busse R (2003) Cytochrome P450 2C9-derived epoxyeicosatrienoic acids induce angiogenesis via cross-talk with the epidermal growth factor receptor (EGFR). FASEB J 17: 770 - 772

NCBI SNP homepage (2008) NCBI SNP homepage Access date 2008-07-15 http://www.ncbi.nlm.nih.gov/SNP/snp_ref.cgi?rs $=1058930$

Sandberg M, Johansson I, Christensen M, Rane A, Eliasson E (2004) The impact of CYP2C9 genetics and oral contraceptives on cytochrome P450 2C9 phenotype. Drug Metab Dispos 32: 484-489

Schroth W, Antoniadou L, Fritz P, Schwab M, Muerdter T, Zanger UM, Simon W, Eichelbaum M, Brauch H (2007) Breast cancer treatment outcome with adjuvant tamoxifen relative to patient CYP2D6 and CYP2C19 genotypes. J Clin Oncol 25: 5187-5193

Walsky RL, Gaman EA, Obach RS (2005) Examination of 209 drugs for inhibition of cytochrome P450 2C8. J Clin Pharmacol 45: 68-78

Yasar U, Eliasson E, Dahl ML, Johansson I, Ingelman-Sundberg M, Sjoqvist F (1999) Validation of methods for CYP2C9 genotyping: frequencies of mutant alleles in a Swedish population. Biochem Biophys Res Commun 254: $628-631$

Yasar U, Lundgren S, Eliasson E, Bennet A, Wiman B, de Faire U, Rane A (2002) Linkage between the CYP2C8 and CYP2C9 genetic polymorphisms. Biochem Biophys Res Commun 299: 25-28

Zeldin DC, DuBois RN, Falck JR, Capdevila JH (1995) Molecular cloning, expression and characterization of an endogenous human cytochrome P450 arachidonic acid epoxygenase isoform. Arch Biochem Biophys 322: $76-86$ 